\title{
La influencia de San Agustín en la doctrina de la creación de Alejandro de Hales
}

\author{
Verónica Benavides \\ UNIVERSIDAD ADOLFO IBÁÑEZ \\ veronica.benavides@uai.cl
}

Resumen: El presente artículo busca poner de manifiesto la influencia filosófica que ejerció San Agustín de Hipona y su doctrina de la creación en el fundador de la Escuela Franciscana del siglo XIII, Alejandro de Hales. De este modo, veremos cómo los principales conceptos halesianos en torno a la creación, tales como la creación in tempore, las Ideas divinas, el ejemplarismo o las razones seminales, tienen un claro origen agustiniano, mientras que otros, como el hilemorfismo universal o la pluralidad de formas sustanciales, provienen de influencias aristotélicas, árabes y judías. Finalmente, proponemos pensar la doctrina halesiana de la creación como parte de una nueva tradición interpretativa de la metafísica agustiniana.

Palabras clave: Creación ex nibilo, agustinismo medieval, ideas divinas, hilemorfismo universal, Escuela Franciscana.

Summary: This article seeks to highlight the philosophical influence that Saint Augustine of Hippo and his doctrine of creation exerted on the Franciscan School of the 13th century founder, Alexander of Hales. In this way, we shall see how the halesian main concepts concerning the creation, such as the in tempore creation, divine Ideas, exemplarism or seminal reasons have a clear Augustinian origin. Whereas others, like the universal hilomorphism or the substantial-forms plurality, come from Aristotelian, arab or jewish influences. Finally, we propose to regard the halesian creation doctrine as part of a new Augustinian metaphysics interpretive tradition.

Keywords: Creation ex nihilo, medieval agustinism, divine ideas, universal hylomorphism, Franciscan School. 


\section{INTRODUCCIÓN}

La mayoría de los estudiosos de la Edad Media concuerda, por una parte, en que San Agustín fue el gran maestro de la Europa medieval en múltiples ámbitos, no solo en el teológico y filosófico. Por otra parte, también hay cierta unanimidad en reconocer que, como lo destaca M.W.F. Stone, hubo una continua tradición de reflexión y comentario de las obras de San Agustín a lo largo de la Edad Media ${ }^{1}$, más allá de las diversas interpretaciones de que fueron objeto. En este sentido, su influencia se dejó sentir en autores tempranos ${ }^{2}$ tales como Juan Scoto Eriúgena y Honorio de Autún, y más adelante con figuras tales como Anselmo de Canterbury, en quien el pensamiento del Obispo de Hipona cobró una importancia decisiva tanto en filosofía como en teología.

Con todo, el pensamiento y las obras de San Agustín encontraron su mejor vehículo de expresión y difusión en el Liber Sententiarum de Pedro Lombardo, ya que, al ser éste el texto de base en las facultades de teología de las nacientes universidades medievales, aseguró la presencia continua de las teorías y preceptos agustinianos en todos los aspectos de la filosofía y teología medieval ${ }^{3}$. De este modo, el siglo XIII dispuso no solo de las principales obras del Obispo de Hipona, sino también de un nutrido cuerpo de autores que, de un modo u otro, perpetuaron el legado de Agustín, elevándolo al grado de auctoritas omnipresente en las Summas de este período.

Ahora bien, que dicha herencia intelectual sea un todo homogéneo a través de la Edad Media, es algo que permanece aún sujeto a discusión. Incluso el mismo término agustinismo medieval es controversial, puesto que no hubo una sino muchas lecturas de Agustín, de manera tal que, como lo sostiene De Wulf siguiendo a Ehrle, el llamado agustinismo no es más que una línea de ideas dominante en los teólogos y filósofos desde

M.W.F. Stone, "Augustine and Medieval Philosophy", en E. Stump-N. KretzMann, The Cambridge Companion to Augustine (Cambridge University Press, Cambridge, 2006) 253.

2 Como lo aclara el P. Cayré: "Saint Augustin fut suivi par les meilleurs penseurs du Haut Moyen âge, Boèce, Cassiodore, et des XIe et XIIe siècles, saint Anselme, Hugues et Richard de Saint-Victor, sans qu'on puisse affirmer l'identité totale de leur doctrine avec celle du maître". F. CAYré, Initiation à la philosophie de Saint Augustin (Études Augustiniennes; Desclée de Brouwer, Paris, 1947) 285.

3 M.W.F. Stone, "Augustine and Medieval Philosophy", en E. Stump-N. KretzMANN, The Cambridge Companion to..., 255. 
el comienzo del siglo XIII hasta Tomás de Aquino y sus continuadores ${ }^{4}$, pero de ningún modo una escuela rígida con un corpus fijo de ideas a defender en nombre de Agustín.

A lo anterior hay que agregar que, paradójicamente, las teorías más representativas del agustinismo medieval son ajenas al pensamiento de San Agustín. Si bien en el caso de la noción de creación hay ideas de inequívoco origen agustiniano, como la teoría de las razones seminales o la creación del mundo en el tiempo, coexisten también ideas eclécticas resultantes de la alianza de conceptos agustinianos con otros elementos disponibles en el Medioevo, como ocurre con la teoría de la iluminación divina, claramente influida por Avicena. Lo más sorprendente, sin embargo, es que el llamado famosissimum binarium augustinianum -el hilemorfismo universal y la pluralidad de formas sustanciales- no pertenece al Obispo de Hipona en modo alguno. En efecto, las doctrinas relacionadas con la materia y la forma son de origen aristotélico, árabe y judío, mientras que el hilemorfismo universal proviene de Ibn Gabirol (Avicebrón) ${ }^{5}$. Luego, el agustinismo medieval más parece ser un crisol de ideas que subyacen en un fondo más o menos común, que una exégesis ortodoxa del pensamiento del Santo Doctor.

En consecuencia, cada generación de pensadores medievales utilizó los elementos de la obra de Agustín que le ayudaron a entender los problemas filosóficos y teológicos de su propia época ${ }^{6}$. En este marco de ideas estudiaremos al fundador de la Escuela Franciscana del siglo XIII, Alejandro de Hales, en cuanto genuino representante del citado agustinismo ${ }^{7}$, dado que se esforzó por entender y dilucidar -entre otros- el problema de la creación del mundo desde el pensamiento de San Agustín, pero sin dejar

4 M. De Wulf, Histoire de la Philosophie Médiévale (Tome deuxième; Institut Supérieur de Philosophie de Louvain- J. Vrin, Louvain-Paris, 1936) 354. El estudio citado por De Wulf es el del cardenal F. Ehrle, Der Augustinismus und der Aristotelismus in der Scholastik gegen Ende des dreizehnten Jahrhunderts, publicado en $1889 \mathrm{y}$, desde entonces, considerado por los especialistas como el comienzo de la discusión erudita sobre el agustinismo y el aristotelismo medieval.

5 M. De Wulf, Histoire de la..., 356.

6 Cfr. M.W.F. Stone, "Augustine and Medieval Philosophy”, en E. Stump-N. KretzMann, The Cambridge Companion to..., 263.

7 No obstante, como afirma De Wulf, no es posible identificar sin más el agustinismo con el pensamiento franciscano: "On ne peut donc pas identifier augustinisme et philosophie franciscaine, bien que les franciscains, par leur nombre et par leur esprit de corps, en aient été les principaux artisans". M. DE Wulf, Histoire de la ..., 354. 
de lado el contexto cultural y las influencias filosóficas de su propia época. Una prueba de ello es que la actitud que adopta sea siempre buscar los elementos filosóficos que le ayuden a explicar el Génesis, siguiendo el espíritu del intellige ut credas, crede ut intelligas agustiniano, pero también recurriendo a autores paganos como Aristóteles o infieles como Avicena, Maimónides o Avicebrón. En este sentido, no hay que olvidar que Alejandro de Hales fue quien primero incorporó las obras de Aristóteles a los estudios teológicos ${ }^{8}$, dando el impulso inicial al grupo de teólogos franciscanos cuya obra consistiría en asimilar el saber filosófico nuevo con ayuda de los principios sentados por San Agustín?. Veamos, pues, tras una breve noticia sobre nuestro autor, de qué manera el halense incorpora la influencia agustiniana a su propia noción de creación.

\section{ALEJANDRO DE HALES (1170/80-1245)}

Nació en Hales Owen, condado de Gloucester (Inglaterra), hacia el 1170-80 y murió en París el 21 de agosto de 1245. Estudió en la Facultad de Artes de la Universidad de París, llegando a ser magister in artibus antes de 1210, año en que comienza a enseñar en dicha universidad ${ }^{10}$. Entre 1226 y 1229 se convierte en Maestro de Teología. Hacia 1231 ingresó en la Orden Franciscana, conservando su cátedra, con lo que el Estudio general de los franciscanos quedó incorporado a la Universidad ${ }^{11}$.

8 Según Christopher M. Cullen, "[Alexander] is the earliest scholastic to engage Aristotle's newly translated writings, in particular, the Metaphysics”. CH. Cullen, "Alexander of Hales", en J. E. Gracia- T. B. Noone, A Companion to Philosophy in the Middle Ages (Blackwell Publishing, Oxford, 2006) 104.

9 E. Gilson, La Filosofía en la Edad Media (Gredos, Madrid, 1995) 430.

10 Cfr. K. Osborne, The History of Franciscan Theology (Franciscan Institute, New York, 1994) 3. La mejor presentación de la vida y obras de Alejandro de Hales se encuentra en el Prolegomena de la edición de su Glossa in Quattuor Libros Sententiarum Petri Lombardi (Vol. I; Collegium S. Bonaventurae, Quaracchi, Florencia, 1951) 7-75. Vid. también: R. Huber, "Alexander of Hales O.F.M", en Franciscan Studies 5 (1945) 353-365.

11 Durante su docencia universitaria Alejandro de Hales formó a los más notables filósofos y teólogos franciscanos de su época, entre los que se cuentan Juan de la Rochelle -su sucesor en la cátedra tras su retiro y posterior muerte en 1245-, Richard Rufus de Cornwall y el mismísimo San Buenaventura, quien llamaba a Alejandro padre y maestro. Cfr. Ch. Cullen, "Alexander of Hales", en J. E. Gracia- T. B. Noone, A Companion to..., 104. Su obra capital es la Summa Theologica o Summa fratris Alexandri, al parecer compuesta no antes de 1231 y terminada por sus discípulos después de la muerte del maestro franciscano, en 1245 . Un completo estudio acerca de la autentici- 
La primera fuente de la que se nutre Alejandro es, evidentemente, las Sagradas Escrituras, seguido por San Agustín, de quien conoce, maneja y cita numerosas obras, así como también de sus seguidores medievales. En este sentido, puede afirmarse con propiedad que "Alejandro de Hales amplió fielmente aquella tradición teológica y filosófica que tiene su origen en San Agustín y sus seguidores"12. Por otra parte, en la Summa Theologica cita a todos los Padres latinos y no omite a los autores griegos ${ }^{13}$, lo que denota su amplio conocimiento de la literatura patrística y la filosofía griega, a la que mira con desconfianza ya que carece de la Revelación cristiana, pero de la que toma todo aquello que no sea incompatible con las verdades de la fe, dando inicio así a una nueva actitud frente al saber pagano que se extenderá hasta los más insignes escolásticos de la Edad Media.

A Aristóteles, como a cualquier otro filósofo pagano, le reprocha la insuficiencia de su doctrina metafísica y su conocimiento deficiente del verdadero Dios, de lo cual se siguen numerosas consecuencias éticas, antropológicas y teológicas que imponen un abismo respecto del cristianismo. En lo que respecta a Dios y la creación, Alejandro impugna las clásicas tesis aristotélicas de la eternidad de la materia ${ }^{14} \mathrm{y}$ de la eternidad del movimiento ${ }^{15}$, enseñando que la eternidad solo le conviene a Dios: “[...] contra el Filósofo enseña que la eternidad propiamente conviene solo a Dios" ${ }^{16}$. No obstante, la influencia del Estagirita igual está presente en la filosofía de Alejandro, pues hace uso de la distinción entre sustancia y accidente, la división aristotélica de las causas y una versión modificada del hilemorfismo ${ }^{17}$.

En suma, la importancia de Alejandro de Hales para la filosofía y la teología de la naciente Escuela Franciscana radica, como lo indica Bou-

dad de la Summa Theologica se encuentra en: V. DOUCET, "The History of the problem of the authenticity of the Summa”, en Franciscan Studies 7 (1947) 26-41.

12 Alexandri de Hales, Summa Theologica, Tomus I, Prolegomena, XXX (iussu et auctoritate Rmi. P. Bernardini Klumper; Ex Typographia Collegii S. Bonaventurae, Ad Claras Aquas, Quaracchi, Florentia, 1924). En adelante, se usará la abreviatura S.Th.

13 Alexandri de Hales, S.Th., I, Prolegomena, XXIX.

14 Alexandri de Hales, S.Th., I, Núm. 133, ad 1 et 2.

15 Alexandri de Hales, S.Th., I, Núm. 64, ad 12, ad 14.

16 Alexandri de Hales, S.Th., I, Prolegomena, XXXIX.

17 Según Merino, todo esto indica su "constante deseo de diálogo tratando de armonizar tesis aristotélicas con el pensamiento agustiniano como asimismo de confrontar los pensadores cristianos con los paganos". J. A. Merino O.F.M., "Filosofía y Teología en la Escuela Franciscana Medieval”, en Angelicum 71/1 (1994) 45. 
gerol, en haberle dado "un cuerpo doctrinal y un espíritu"18, es decir, en haber creado una nueva síntesis entre agustinismo, patrología y filosofía greco-árabe, muy distante aún del llamado agustinismo avicenizante ${ }^{19}$ que en la segunda mitad del siglo XIII se opondrá al aristotelismo averroísta. En lo que respecta al presente estudio, nos centraremos en la influencia de la doctrina agustiniana de la creación en la reflexión del maestro de Hales sobre el mismo tema, a fin de corroborar hasta qué punto se impone ésta a los nuevos elementos asimilados a ella por nuestro autor.

\section{ALEJANDRO DE HALES Y LA NOCIÓN DE CREACIÓN}

La noción halesiana de creación se encuentra presente en todas sus obras, pero es en la Summa Theologica donde se halla expuesta con mayor claridad, en el Liber Primus (De Deo) y en el Liber Secundus (De Creatura), de clara influencia agustiniana, esto es, de aquella proveniente del Agustín repensado por San Anselmo y aumentado por las especulaciones originadas en San Víctor ${ }^{20}$.

En esta línea de pensamiento, y en concordancia con los Padres de la Iglesia, Alejandro sostiene en la Summa que la Voluntad de Dios es la causa primera y suprema de todas las creaturas: “[...] su gratuita voluntad creó las creaturas" 21 , e invoca para probarlo la autoridad del mismo Agustín, citándolo profusamente ${ }^{22}$. Dada la gratuidad absoluta del acto creador divino, es evidente que no hay necesidad alguna por parte de Dios al crear, es más, el mismo término -sostiene el maestro de Hales, siguiendo a San Anselmo- repugna a la noción de $\operatorname{Dios}^{23}$. Por lo tanto, solo Dios crea y lo hace siguiendo su libérrima Voluntad ${ }^{24}$.

18 J.-G. Bougerol, Introduction à l'étude de Saint Bonaventure (Desclée et Cie. Éditeurs, Tournai, 1961) 50.

19 El término agustinismo avicenizante fue acuñado por Étienne Gilson en su artículo "Les sources gréco-arabes de l'Augustinisme Avicennisant", en Archives d'Histoire Doctrinale et Littéraire du Moyen Âge I (1929) 80.

20 Cfr. J.-G. Bougerol, Introduction à l'étude..., 51.

21 Alexandri de Hales, S.Th., II, Núm. 18, Solutio (iussu et auctoritate Rmi. P. Bonaventurae Marrani; Ex Typographia Collegii S. Bonaventurae, Ad Claras Aquas, Quaracchi, Florentia, 1928).

22 San Agustín, De Trinitate, III, 4, 9; De Diversis Quaestionibus 83, q. 28; De Civitate Dei, XI, 24.

23 Alexandri de Hales, S.Th., II, Núm. 18, ad 1.

24 Alexandri de Hales, S.Th., II, Núm. 18, ad 5. 
De este modo, si crear es un acto exclusivo de Dios, ninguna creatura -ni siquiera un ángel- puede poseer potencia creadora, ya que ésta no es una capacidad que esté incluida en su naturaleza ${ }^{25}$, es decir, en su condición de ser sacado de la nada. Y la razón que esgrime Alejandro es muy poderosa: "Si la potencia de crear todas las cosas que es propia de Dios se atribuyera a la creatura, ésta tendría la potencia de crearse a sí misma, y, así, sería causa de ella misma"26. En este sentido, ninguna creatura podría tampoco participar en el acto creador divino (nec esse particeps in opere creationis), vale decir, ser con-causa o causa concomitante de la creación, pues esto sería igualar en poder a la creatura con el Creador. Como lo sostiene el maestro franciscano, lo propio de la creatura es obrar sobre una materia ya creada, y no cooperar en la producción de las formas ${ }^{27}$, obra exclusiva de Dios. Su rol es, más bien, "disponer de las cosas menos nobles, instando a Dios a la producción de las cosas más nobles" ${ }^{28}$, pues, como ya lo había manifestado San Agustín, a quien cita Alejandro en este pasaje $\mathrm{e}^{29}$, las creaturas, ya sean ángeles u hombres, solo obran exteriormente, mientras Dios es el único que obra desde dentro (interius operatur) de los entes creados.

\section{LA FÓRMULA CREATIO EX NIHILO}

En este punto, el Doctor Irrefragabilis sigue de cerca las Sagradas Escrituras y la tradición unánime de los Padres de la Iglesia y del mismo Agustín sobre cómo debe entenderse la noción de creación: crear, en sentido propio, es "hacer todo de la nada, y es así que se dice «En el principio creó Dios el cielo y la tierra»" ${ }^{30}$. Esto significa que Dios crea todo lo que es de la nada absoluta (ex nihilo), sin que haya una materia previa para efectuar la obra creadora ${ }^{31}$. No obstante, el Maestro de Hales advierte

25 Alexandri de Hales, S.Th., II, Núm. 24, Contra. En la Solutio de este número, Alejandro respalda su afirmación recurriendo, una vez más, al testimonio de San Agustín en De Trinitate, III, 8, 13 y en De Genesi ad Litteram, V, 4, 11/ IX, 15, 26-28.

26 Alexandri de Hales, S.Th., II, Núm. 24, ad 1.

27 Alexandri de Hales, S.Th., II, Núm. 48, ad 1.

28 Alexandri de Hales, S.Th., II, Núm. 48, ad 1.

29 San Agustín, De Trinitate, III, 8, 14: “[...] ita creationem rerum visibilium Deus interius operatur". Para respaldar la tesis que las creaturas no pueden crear en sentido propio, Alejandro vuelve ad auctoritatem Augustini y cita el De Diversis Quaestionibus 83, q. 78.

30 Alexandri de Hales, S.Th., II, Núm. 21, Solutio.

31 Alexandri de Hales, S.Th., II, Núm. 48, Contra. 
del riesgo que se corre al malentender el significado de la expresión nihil: ser creado es ser hecho de la nada en el sentido que la creatura llega al ser después de no haber sido en absoluto ${ }^{32}$, y no en el sentido que el no-ser sea la materia ex qua Dios crea a los entes ${ }^{33}$, como si la nada fuera una sustancia real, pues en ese caso la potencia divina no sería más que un agente demiúrgico al estilo platónico.

Por otra parte, ante la pregunta si la creación ex nibilo es algún tipo de mutación o cambio, Alejandro señala que, para la creatura, ser creada es y no es una mutación, según el modo en que se tome el verbo mutar. Llegar al ser no es una mutación, pues toda mutación es un paso de la potencia al acto, y antes de ser creada en la creatura no hay ni potencia ni acto $^{34}$. Sin embargo, tomado desde el punto de vista de su constitución ontológica, lo propio de la creatura es precisamente la mutación y el cambio; dado que su ser es recibido, ella no es de illo, sino que ha sido hecha ex nibilo, lo cual le impone necesariamente la marca de la contingencia y el cambio ${ }^{35}$. Así, queda establecida la radical diferencia entitativa entre la creatura y el Creador, pues mientras aquella es finita y cambiante, Dios es inmutable y eterno ${ }^{36}$, ya que es su propio ser, Él es el Ser en sí, afirmación que le permite a Alejandro de Hales combatir toda suerte de panteísmo proveniente de las diversas herejías que -en pleno siglo XIII- buscaban homogeneizar el ser de Dios y el mundo, tal como ya había argumentado Agustín en su célebre pasaje del De Natura Boni, XXVII ${ }^{37}$.

Otro rasgo interesante de la noción halesiana de creación, y en el cual se nota claramente la impronta agustiniana, es la distinción entre creatio

32 AleXandri de Hales, S.Th., II, Núm. 50, Solutio: “[...] et secundum hunc modum dicitur 'creari' fieri ex nihilo vel de nihilo, quia post omnino non-esse procedit creatura in esse". El argumento paralelo al citado puede encontrarse en SAN AGUSTín, De Civitate Dei, XII, 1, 3.

33 Alexandri de Hales, S.Th., II, Núm. 50, ad 2.

34 Alexandri de Hales, S.Th., II, Núm. 41, Resp.

35 Vid. AleXandri de Hales, S.Th., II, Núm. 41, ad 1-2, donde el maestro franciscano apela a la autoridad de San Isidoro de Sevilla y San Agustín para probar su aserto.

36 Alexandri de Hales, S.Th., II, Núm. 23, ad 2.

37 San Agustín, De natura Boni contra Manichaeos, XXVII: "Ex ipso autem non hoc significat, quod de ipso. Quod enim de ipso est, potest dici ex ipso: non autem omne quod ex ipso est, recte dicitur de ipso. Ex ipso enim caelum et terra, quia ipse fecit ea: non autem de ipso, quia non de substantia sua”. 
y factio como dos aspectos de la creación ex nibilo ${ }^{38}$. Recordemos que San Agustín se refería a creatio y formatio como dos efectos diferentes pero simultáneos del mismo acto creador divino ${ }^{39}$, donde uno corresponde a la creación de la materia informe, y el otro al acabamiento de la misma por la forma. En el caso de la distinción acuñada por Alejandro, creatio designa la creación de la materia informe, tal como lo afirma en la Summa Theologica ${ }^{40}$. Por otra parte, factio designa la creación de las formas según el orden querido por Dios ${ }^{41}$, a fin de dar acabamiento a la materia y traer al ser a las cosas creadas como tales, a las que llama, como Agustín, "las que son formadas" (ea quae formata sunt) ${ }^{42}$. Obviamente, para ambos autores, estos dos momentos de la creación ex nihilo no tienen relación alguna con una sucesión temporal, pues han sido realizados por Dios como un solo e indivisible acto creador: "[...] así, no se dice anterior o posterior [...] sino simultáneo" ${ }^{43}$. Es más, para Alejandro todo ha sido creado en un único nunc, que no es el de la eternidad divina, ni el del decurso temporal, sino el que marca el principio de las creaturas y el tiempo que les es inherente ${ }^{44}$.

\section{CREACIÓN TEMPORAL VERSUS CREACIÓN ETERNA}

Si, como decíamos más arriba, el mundo ha sido creado en un solo acto simultáneo e indivisible de la potencia divina, queda por preguntarse con el maestro de Hales si es ésta una creación temporal o eterna. Cabe señalar que esta pregunta, como tal, no está presente en las obras de

38 Alexandri de Hales, S.Th., II, Núm. 251, Solutio: “[...] creare caelum et terram dicitur dupliciter: vel informem materiam facere vel per species et formas distinguere".

39 Vid. San Agustín, De Fide et Symbolo, II, 2.

40 Alexandri de Hales, S.Th., II, Núm. 22, ad 2: "creare respiciat materiam informem".

41 Alexandri de Hales, S.Th., II, Núm. 250, ad 2: "factio enim respicit formas distinctas, ubi ordo designatur".

42 Alexandri de Hales, S.Th., II, Núm. 22, ad 2, p. 34. En De Fide et Symbolo, II, 2, Agustín llama a las creaturas "quaecumque formata sunt".

43 Alexandri de Hales, S.Th., II, Núm. 250, ad 2. Demás está decir acá que las fuentes que sigue el maestro de Hales son las Sagradas Escrituras (Eccl. XVIII, 1: "Qui vivit in aeternum creavit omnia simul") y el mismo San Agustín (De Fide et Symbolo, II, 2; De Genesi ad Litteram, V, 5, 13). En la Solutio de este mismo número, Alejandro añade además la autoridad de Hugo de San Víctor.

44 AleXandri de Hales, S.Th., II, Núm. 250, III, Solutio. 
San Agustín con la fuerza que lo estará en el siglo XIII, pues el Santo da por demostrado -ante las objeciones maniqueas- que el mundo ha sido creado cum tempore ${ }^{45}$, interpretando aquel in principio genesíaco (Gen., I, 1) como el principio mismo del mundo y de los tiempos.

Una vez que se conocieron las traducciones árabes de los textos de Aristóteles, en especial la Física y la Metafísica, la posibilidad de una creación eterna cobró fuerza en las universidades medievales, a tal punto que se transformó en la quaestio más disputada en el siglo XIII ${ }^{46}$. En este contexto, Alejandro rechaza la eternidad del mundo ex parte initii, ex parte finis y ex parte motus en clara alusión a las tesis aristotélicas al respecto. Siguiendo a Agustín declara categóricamente que el mundo no es eterno, pues la eternidad se dice de lo que no tiene principio de duración ni fin ${ }^{47}$; de allí que, a su juicio, la idea de un mundo eterno "deba ser reprobada como enemiga de la fe, al devenir contraria a la Ley y los Profetas" ${ }^{38}$, fórmula casi idéntica a las palabras de San Agustín al respecto: "[...] no afirmemos que alguna creatura es coeterna con el Creador, pues lo condena la fe y la sana razón $[\ldots]$ ”²9.

Consideremos, en primer lugar, el detalle de la refutación halesiana a los argumentos que defienden la eternidad del mundo ex parte initii, es decir, en cuanto a su origen en la voluntad y potencia creadora de Dios. En primer lugar, el gastado argumento maniqueo -ya resuelto por San Agustín (vid. De Civ. Dei, XII, 16-17)- de la supuesta ociosidad divina

45 San Agustín, De Civitate Dei, XI, 6: "[...] procul dubio non est mundus factus in tempore, sed cum tempore”. Vid. además De Civitate Dei, XI, 4, 2; De Genesi ad Litteram imperfectus Liber, III, 8.

46 Ch. Cullen, "Alexander of Hales", en J. E. Gracia- T. B. Noone, A Companion to..., 107. Entre 1220 y 1230, época en que Alejandro de Hales compone una serie de cuestiones sobre la eternidad del mundo, ya hay un intenso debate sobre el concepto cristiano y pagano de eternidad, sobre la definición de eternidad que da Boecio en De Consolatione Philosophiae y la duración a parte ante del universo. Así lo atestiguan las Quaestiones de aeternitate de William of Durham (Douai, Bibliothèque Municipale MS 434) y textos anónimos que llevan por título Questiones tres de eternitate (Douai, Bibliothèque Municipale MS 434) o Si potuit Deus facere mundum ab eterno (Douai, Bibliothèque Municipale MS 434), los cuales, según Dales y Argerami, podrían corresponder a escritos de maestros franciscanos de París. Vid. R. C. Dales- O. ArgeRAMI, Medieval Latin texts on the Eternity of the World (E.J. Brill, Leiden, 1991).

47 Sobre el concepto halesiano de eternidad, vid. R. C. DALES, "Time and Eternity in the Thirteenth Century", en Journal of the History of Ideas 49/1 (1988) 29-31.

49 San Agustín, De Civ. Dei, XII, 15, 1. 
antes de crear vuelve a tomar fuerza, ante lo cual Alejandro deja en claro que la bondad divina "nunca estuvo ociosa" ${ }^{50}$, pues, respecto de la eternidad, la procesión divina es desde siempre, y respecto del tiempo, Dios no pasó del ocio a la actividad creadora, ya que no hay un antes temporal respecto del cual pueda decirse que el crear es posterior a la decisión libérrima de crear ex nibilo ${ }^{51}$. Por lo tanto, una cosa es que la bondad divina esté actuando ab aeterno, desde siempre, sin atisbo de vacancia, y otra que el mismo mundo sea eterno como consecuencia de lo anterior. Si así fuese, las creaturas serían coeternas con el Creador ${ }^{52}$, lo cual es, a todas luces, contradictorio.

Otra objeción radica en el mal entendimiento de la eternidad de la voluntad de Dios: si, desde esa misma eternidad, primero no quiso hacer el mundo ab aeterno y posteriormente sí lo quiso, eso muestra que hay mutación en la voluntad divina. Sin embargo, en la voluntad de Dios no hay mutación -responde el maestro de Hales- en el sentido de que haya un antes y un después de la determinación adoptada, como sucede en el caso de la voluntad humana ${ }^{53}$; de allí que ab aeterno haya querido crear las cosas que serían en el tiempo, de lo cual se sigue que la decisión divina es eterna e inmutable, pero su efecto es temporal, no eterno ${ }^{54}$. Por lo tanto, la mutación no está en la voluntad divina, sino en las cosas creadas: "el cambio estaría del lado de las cosas creadas" 55 . En ellas se da la mutación como su constitutivo propio, de modo que por naturaleza no les conviene la permanencia que supone la eternidad.

En definitiva, la razón más poderosa que esgrime Alejandro contra la eternidad del mundo ex parte initii descansa en que, si bien Dios desde siempre quiso y pudo crear el mundo, su voluntad quiso hacer las cosas temporalmente, esto es, en el tiempo o con el tiempo ${ }^{56}$, y no de otro modo. Así pues, concordando con lo sostenido por San Agustín ${ }^{57}$, el

\footnotetext{
Alexandri de Hales, S.Th., II, Núm. 67, ad 1.

Alexandri de Hales, S.Th., II, Núm. 67, ad 1.

AleXANdri de Hales, S.Th., II, Núm. 67, ad 12.

Alexandri de Hales, S.Th., II, Núm. 67, ad 3.

Alexandri de Hales, S.Th., II, Núm. 67, ad 5.

55 Alexandri de Hales, S.Th., II, Núm. 67, ad 2. Para mayor abundamiento sobre la inmutabilidad de la voluntad divina, vid. ad 3, ad 4 y ad 9.

56 Alexandri de Hales, S.Th., II, Núm. 67, ad 7.

57 San Agustín, De Genesi contra Manichaeos, I, 2, 4: "Cum ipsa creatura, quam fecit Deus, tempora esse coeperunt".
} 
maestro franciscano establece que el tiempo es paralelo (coaevum) a la existencia de las creaturas ${ }^{58}$, dado que éste es la medida de los cambios en aquello que ha pasado del no-ser al ser ${ }^{59}$. Luego, si el tiempo es intrínseco a las creaturas desde el momento mismo en que llegan al ser, no hay lugar para sostener la eternidad del mundo creado.

Respecto de la cuestión Utrum mundus sit aeternus ex parte finis, Alejandro distingue dos posibilidades a considerar: si este mundo no tiene fin y si después de este mundo habrá otro mundo, en una suerte de renovación universal perpetua. Respecto del primer caso, nuestro autor es categórico: si se entiende por mundus el conjunto de todas las cosas corruptibles e incorruptibles, inferiores y superiores, es claro que el mundo no es eterno respecto de su duración o fin ${ }^{60}$. Sin embargo, a diferencia de la discusión anterior, los argumentos con que apoya esta tesis corresponden, más que a razones metafísicas, a razones teológicobíblicas, invocando una sola vez la autoridad de San Agustín en cuanto exégeta del Antiguo Testamento y no en cuanto filósofo ${ }^{61}$.

Por otra parte, la hipótesis de una renovación perpetua de los seres requiere de una distinción: de acuerdo al maestro de Hales no existe repetición de los seres en cuanto al número, sino en cuanto a las especies, particularizadas en individuos diferentes, en una sucesión ordenada según el antes y el después ${ }^{62}$. En buenas cuentas, no hay una cantidad fija de creaturas que se reitere perpetuamente, en una continua revolución cósmica, de lo cual se sigue que el mundo no es, en este sentido, eterno ex parte finis. Tampoco es posible admitir el eterno retorno de los mismos seres y de las mismas circunstancias, en una especie de circuitus saeculorum como el planteado por los filósofos griegos, pues, de ser así, ni la misma muerte y resurrección de Cristo escaparían a este acontecer circular. Esta tesis, aparte de ser metafísicamente incompatible con la potencia divina, es rechazada por Alejandro principalmente por ser contraria a la fe: en último término, sostiene, el fin del mundo está en

\footnotetext{
58 Alexandri de Hales, S.Th., II, Núm. 49, Contra, 1.

59 Alexandri de Hales, S.Th., II, Núm. 49, ad 1: "Dicendum quod tempus accipitur ibi pro mensura mutationis, quae subito fit sive exitus rei de non-esse in esse".

60 Alexandri de Hales, S.Th., II, Núm. 68, Solutio, I.

61 AleXandri de Hales, S.Th., II, Núm. 68, I, Circa quod sit, 1-4.

62 Alexandri de Hales, S.Th., II, Núm. 68, Solutio, II. Vid. también ad 1.
} 
la voluntad del Creador una vez completo el número de los elegidos ${ }^{63}$, y no en el eterno retorno de lo igual.

Finalmente, Alejandro de Hales aborda el problema de la eternidad del mundo ex parte motus, el cual está representado, en su mayor parte, por las afirmaciones sobre la naturaleza del movimiento vertidas por Aristóteles en la Física. En este contexto, ya en el Contra se presenta una razón de peso, curiosamente de inspiración aristotélica, para rechazar este tipo de eternidad del mundo: el movimiento es el paso de la potencia al acto, pero la potencia existe previamente a su actualización, por lo tanto -concluye nuestro autor-todo lo que tiene una causa anterior a su producción no es eterno. De este modo, ningún movimiento es eterno ${ }^{64}$. Incluso más, valiéndose de la frase de Aristóteles "todo movimiento tiene su origen en lo inmóvil" ${ }^{65}$, deduce que, como lo inmóvil es anterior al movimiento, éste, al tener un principio, no es eterno ${ }^{66}$.

En la respuesta a la cuarta objeción de esta cuestión (Núm. 69), el Maestro franciscano trae a colación un argumento que, tiempo después, también tomará San Buenaventura en su Comentario a las Sentencias ${ }^{67}$, y que deja clara la imposibilidad metafísica de la eternidad del movimiento, y por ende, del mundo en cuanto sujeto a éste. En efecto, el tiempo, en que se da el movimiento, tiene un comienzo en el ser (incipit esse), pero ese comienzo no es sino aquel nunc, principio de todos los tiempos ${ }^{68}, \mathrm{y}$ que no supone temporalidad anterior alguna, ya que antes de este nunc solo existe Dios; en consecuencia, si el tiempo ha tenido un comienzo, el movimiento también, pues ambos se dan simultáneamente en la realidad. Y si esto es así, el mundo no puede ser eterno ex parte motus.

En último término, y valiéndose de la doctrina agustiniana de las Ideas divinas, Alejandro de Hales rechaza la eternidad del mundo basada en la coeternidad de los arquetipos y del universo formado a imitación de aquellos. En efecto, los arquetipos del mundo preceden al mundo sensible en cuanto a su origen y su eternidad (son Dios mismo), de

\footnotetext{
Alexandri de Hales, S.Th., II, Núm. 68, II, ad b-c.

Alexandri de Hales, S.Th., II, Núm. 69, Contra, $b$.

Aristóteles, Física, VIII, 5-9.

Alexandri de Hales, S.Th., II, Núm. 69, Contra, $c$.

67 San Buenaventura, II Sent., d. 1, p. 1, a. 1, q. 2, ad 4.

68 Alexandri de Hales, S.Th., II, Núm. 69, ad 4.
} 
modo que ambos no pueden tener la misma duración ${ }^{69}$, pues esto equivale a igualar a la creatura con Creador.

En suma, la oposición de Alejandro a todas estas maneras de sostener la eternidad del mundo tienen por denominador común una implacable lógica argumentativa, pero por sobre todo, la impronta filosófica agustiniana sumada al ardiente deseo de defender la fe ante las amenazas de la filosofía aristotélica que recién comienza a ganar adeptos en la Universidad de París.

\section{LAS IDEAS DIVINAS}

La doctrina halesiana de las Ideas divinas es quizás una de las que denota más claramente la influencia agustiniana sobre nuestro autor, tal como lo señalan los Padres Editores de Quaracchi: "Alejandro de Hales propone y sostiene ampliamente el ejemplarismo de San Agustín"70. De hecho, la mayor parte de su exposición está centrada en el clásico texto de San Agustín De Diversis Quaestionibus 83, q. 46, 2, al que Alejandro glosa detalladamente en su Summa Theologica. Allí, como también lo hizo el Obispo de Hipona, parte declarando a Dios como la causa ejemplar de todo lo creado: "Dios es el [modelo] ejemplar de todas las creaturas que han sido hechas por Él" 71 . Por lo tanto, para el maestro franciscano Dios es el arquetipo o modelo del mundo sensible ${ }^{72}$, en cuya mente se encuentran las Ideas o rationes ${ }^{73}$ que imitan todas las creaturas sicut exemplatum exemplari, cada una según su grado y modo de ser.

De esta manera, las Ideas divinas son causas ejemplares ${ }^{74}$, exemplares o rationes rerum - tal como lo aclara también San Agustín al inicio de la q. 46, 2-, siendo ambas denominaciones diferentes secundum nomen, pero lo mismo secundum rem $^{75}$, ya que las Ideas divinas son la misma

69 Alexandri de Hales, S.Th., I, Núm. 64, ad 2.

70 Alexandri de Hales, S.Th., Tomus I, Prolegomena, XXXI.

71 Alexandri de Hales, S.Th., I, Núm. 175, I.

72 Alexandri de Hales, S.Th., II, Núm. 4, In contrarium, a.

73 Para respaldar esta tesis, Alejandro cita las palabras de San Agustín en De Civitate Dei, VII, 28: "Ideae sunt in mente divina". Cfr. Alexandri de Hales, S. Th., I, Núm. 175, I.

74 Alexandri de Hales, S.Th., II, Núm. 10, Videtur, 2. En este punto, Alejandro transcribe íntegramente el pasaje agustiniano del De Diversis Quaestionibus 83, q. 46, 2, en que San Agustín define la naturaleza y función de las Ideas divinas.

75 Alexandri de Hales, S.Th., I, Núm. 175, I, Respondeo. 
Sabiduría divina, son Dios mismo ${ }^{76}$, como ya se dijo. En este punto, al igual que el Santo Doctor, Alejandro precisa el modo exacto en que debe entenderse la doctrina de la pluralidad de ideas divinas frente a la absoluta simplicidad de la essentia Dei, dadas las múltiples herejías que aun, en pleno siglo XIII, pretenden negarla.

Por una parte, las razones o ideas divinas son muchas (plures), pues ellas son los ejemplares de todas los entes creados, esto es, aquello que fundamenta y explica toda la diversidad que ellos suponen. De allí la riqueza ontológica de la creación, en que cada ser encuentra su referente en una idea divina pensada y querida desde siempre por Dios. No obstante, esto no significa que peligre la simplicidad divina: "las razones e ideas son muchas, sin embargo una es la sabiduría de Dios"77. En las Ideas en cuanto ejemplares no hay pluralidad esencial (non enim est ibi pluralitas in essentia $)^{78}$, la pluralidad se dice ex parte res ideata, es decir, desde el punto de vista de las cosas que se asemejan a estos modelos eternos ${ }^{79}$, las que, en cuanto creadas, difieren de la esencia una y simple del Creador.

Desde esta perspectiva, Alejandro establece una clara distinción metafísica entre Dios y el mundo al sostener que "la esencia de Dios no es la esencia de la creatura" ${ }^{\prime 0}$ : mientras a Dios le corresponde el esse simpliciter, a las creaturas, por haber sido sacadas de la nada, les compete el esse secundum quid ${ }^{81}$. De allí que, al ser esta distinción tan clara y radical, el maestro franciscano piense que no cabe un término medio entre ambos modos de ser, como lo creían ciertos herejes que, inspirados por Escoto Eriúgena, sostenían que las ideas eran el medio entre el Creador y las creaturas $^{82}$. Y su argumento es impecable: "todo lo que es, o es Creador o es creatura, luego es inútil poner un medio entre ellos" ${ }^{\prime 3}$. En consecuencia, la creación es una obra de la omnipotencia divina que no depende

76 Alexandri de Hales, S.Th., I, Núm. 175, VI, Respondeo: "Haec autem rationes sunt ipsa Dei sapientia, quae aeternaliter est".

77 Alexandri de Hales, S.Th., I, Núm. 175, II.

78 Alexandri de Hales, S.Th., II, Núm. 10, Ad obiecta, 1.

79 Alexandri de Hales, S.Th., I, Núm. 175, III, Respondeo.

80 Alexandri de Hales, S.Th., I, Núm. 175, VI, Respondeo.

81 Cfr. Alexandri de Hales, S.Th., I, Núm. 175, V, Respondeo, 4.

82 La obra de Escoto Eriúgena a la que se refiere Alejandro de Hales es Peri Physeon, III, n. 20.

83 Alexandri de Hales, S. Th., II, Núm. 43, Contra, a. Vid. también el Respondendum del mismo número. 
de un demiurgo ni de Ideas subsistentes coeternas para dar el ser, puesto que si Dios es un verdadero Dios, no los necesita.

Con todo, si bien ya está dilucidado el modo de conciliar la simplicidad divina con la pluralidad de ideas ejemplares in mente Dei, el Doctor de Hales se pregunta cuál es la causa de la multitud, es decir, por qué razón Dios, que es uno y simple, crea lo múltiple y diverso. La respuesta, tal como la enuncia, está imbuida del espíritu agustiniano: Dios ha creado la diversidad creatural como manifestación de su divina potencia, sabiduría y bondad ${ }^{84}$. Según Alejandro, su potencia se manifiesta más en la creación de muchas cosas que en la unicidad (plus in multitudine quam in unitate), su sabiduría en la ordenación de muchas cosas (in multorum ordinatione) y su bondad en la perfección de muchas cosas (in multitudinis perfectione), de manera que la creación completa es un todo múltiple, ordenado y suficiente en cuanto a su perfección ${ }^{85}$. Por lo tanto -concluye el franciscano- Dios no ha creado la multiplicidad creatural por indigencia o insuficiencia de su parte, como le acontece a las obras acometidas por la voluntad humana, sino por sobreabundancia de su divina bondad (ex supereffluentia divinae bonitatis), que no es otra cosa que la divina comunicación del ser según todas sus diferencias ${ }^{86}$. Dicha supereffluentia halesiana no es otra cosa que la plenitudo bonitatis señalada por San Agustín en Conf. XIII, 2, 2 como causa de la existencia y la subsistencia de las creaturas.

\section{EL EJEMPLARISMO DIVINO Y LOS SERES CREADOS}

Como hemos visto, el Doctor Irrefragabilis asume íntegramente la doctrina agustiniana de las Ideas divinas y la noción de participación inherente a

84 Alexandri de Hales, S.Th., II, Núm. 55, Solutio: "Si vero quaeratur quare producta est rerum diversitas prima, respondendum est: ad manifestationem divinae potentia, sapientiae et bonitatis".

85 Alexandri de Hales, S.Th, II, Núm. 55, Solutio.

86 Alexandri de Hales, S.Th., II, Núm. 55, Solutio: “[...] non ex indigentia, sed ex supereffluentia divinae bonitatis, cuius est communicare esse secundum omnem eius differentiam". Un par de textos sorprendentemente paralelos pueden encontrarse en San Agustín, De Civitate Dei, XI, 24: “[...] Deum nulla necesitate, nulla suae cuiusquam utilitatis indigentia, sed sola bonitate fecisse quod factum est, id est, quia bonum est [...]". Y De Genesi ad Litteram, I, V, 11: "Inest enim Deo benignitas summa et sancta et iusta et quidam non ex indigentia, sed ex beneficientia ueniens amor in opera sua”. 
ella: cada creatura es deudora de los arquetipos presentes en la mente divina, de tal manera que todo lo que es, es a imitación de las perfecciones del Creador. Si, como lo afirma Van Steenberghen, el pensamiento agustiniano es una filosofía de la participación $n^{87}$, la metafísica halesiana no puede sino ser su prolongación natural, ya que retoma las consecuencias que se siguen del ejemplarismo desarrollado por el Obispo de Hipona.

Así, por ejemplo, Alejandro de Hales sostiene -siguiendo y citando a Agustín- que todo ha sido creado por Dios con un orden jerárquico que va de lo menos noble a lo más noble, siendo ésta una gradación ontológica secundum dignitatem ${ }^{88}$, y dentro de ello, según lo anterior y lo posterior ${ }^{89}$. Es interesante notar acá cómo nuestro autor está plenamente consciente de la historia doctrinal de la noción de orden jerárquico, ya que no solo cita a San Agustín (De Gen. ad Litt., IV, 33 y 34) como autoridad intelectual en el tema, sino también a Juan Damasceno (De Fide Orthod., II, 3), San Gregorio Magno (Moral., XXXII, 12, 17), San Jerónimo (In Epist. ad Tit., 1, 3 sq.) y probablemente-bajo la denominación de aliorum expositorum- a Pedro Lombardo (II Sent., d.12, c.2) ${ }^{90}$.

Para el halense, el mundo entero trasluce un orden que se encuentra inserto en la esencia misma de las creaturas como parte constitutiva de su ser y que hace que cada ente tenga un lugar preciso en el conjunto de lo creado. En este sentido, es claro que el Maestro de Hales hace suya la definición de ordo que da San Agustín en De Civitate Dei, XIX, 13, 191, concordando también en la causa de este ordo rerum, la cual no es otra que el poder, la sabiduría y la voluntad divina que actúan en un solo e indiviso acto $^{92}$.

Ahora bien, supuesto el orden de la creación y la semejanza de las creaturas al Creador mediante el ejemplarismo divino, nuestro autor plantea la tríada característica de toda creatura en relación a Dios, de

87 F. Van Steenberghen, Introduction Générale à les Oeuvres de Saint Augustin, Tome I, 44, en Oeuvres de Saint Augustin (Desclée de Brouwer, Paris, 1949).

88 Alexandri de Hales, S.Th., II, Núm. 47, Respondendum.

89 Alexandri de Hales, S.Th., II, Núm. 89, Solutio. Nuevamente, Alejandro remite el respaldo de esta doctrina a San Agustín, De Genesi ad Litteram, VIII, 23, 44.

90 Cfr. Alexandri de Hales, S.Th., II, Núm. 47, citas 5-9.

91 "Ordo est parium dispariumque rerum sua cuique loca tribuens dispositio". Vid. Alexandri de Hales, S.Th., II, Núm. 86, Caput I.

92 AleXandri de Hales, S.Th., II, Núm. 90, Solutio, 1. Las autoridades citadas acá son San Gregorio Magno (Moral., XXVI, 12, 18) y San Agustín (De Civitate Dei, V, 8). 
clara influencia agustiniana: mensura, numerus et pondus ${ }^{93}$. Todo lo que es, sea en grado mínimo o máximo, posee estos tres rasgos propios y distintivos, los cuales únicamente le convienen a los seres creados dada su ordenación a Dios ${ }^{94}$. Por su parte, Dios es mensura, numerus et pondus en términos absolutos; esto es, como dice Agustín, medida sin medida o medida por la cual es toda medida, número sin número y pondus sine pondere ${ }^{95}$. Pero ¿qué entiende el maestro franciscano por estas tres nociones acuñadas por el Santo Doctor? Para él, mensura es la disposición según la cual la creatura es en sí misma finita en cuanto al ser y sus potencias, numerus se dice en cuanto posee species et forma, lo cual, además, la distingue de otros seres, y pondus es la disposición según la cual la creatura se ordena a su fin ${ }^{96}$. Como se ve, Alejandro conserva el sentido primario que le atribuyó Agustín a mensura, numerus et pondus, y que puede notarse en el paralelismo del pasaje citado de la Summa con el texto de De Genesi ad Litteram, IV, 3, 7, al punto de hacerlas equivalentes -al igual que Agustín- a la tríada ordo, modus et species y a otros trinomios análogos ${ }^{97}$.

Esto nos indica que toda creatura, desde lo más íntimo de su esencia, está referida a Dios por la vía de la semejanza y la participación del Ser en sí, conforme al grado de ser que ha recibido. De allí que el filósofo medieval, retomando una larga tradición de inspiración bíblica y patrística, declare que en toda creatura hay un vestigio del Creador ${ }^{98}$, apoyado no solo en la autoridad de San Agustín (De Trinitate, V, 10), sino también de autores tan diversos como San Gregorio Magno (Moral., X, 8) e Isidoro de Sevilla (De Summo bono, I, 4, 2). Así, para el Doctor de Hales, en sentido primario un vestigium es la impresión de una figura-como la que deja el pie- en el polvo u otro elemento, es decir, lo que común-

93 Alexandri de Hales, S.Th., II, Núm. 28, Solutio, 4.

94 Alexandri de Hales, S.Th., II, Núm. 29, Quod Videtur, 1.

95 SAn Agustín, De Genesi ad Litteram, IV, 4, 8. Este mismo pasaje es citado por Alejandro de Hales en la Solutio del Núm. 29, p. 42, haciéndose eco del clásico texto de Sap. XI, 21: "omnia in mensura et numero et pondere disposuisti”.

96 AleXandri de Hales, S.Th., II, Núm. 27, Solutio.

97 Cfr. Alexandri de Hales, S.Th., II, Núm. 33, Solutio. Allí el Maestro franciscano cita también las tríadas agustinianas quo constat, quo congruit, quo discernitur, y essentia, virtus et operatio, explicitando el sentido particular en que se debe entender cada una, aun cuando todas remiten a la misma realidad creatural.

98 Alexandri de Hales, S.Th., II, Núm. 36, Videtur, a. Un parágrafo más adelante, en la letra b, sostiene nuevamente: "ratio vestigii inest omni creaturae". 
mente llamamos huella. Pero como la esencia divina y la misma Trinidad es infigurable, es imposible que deje una figura a modo de vestigio en las cosas creadas ${ }^{99}$. Por lo tanto, la noción de vestigium no puede ser entendida ni aplicada en este sentido material.

Así, como la semejanza (similitudo) no puede provenir de una figura a cuya imitación las cosas se relacionen ontológicamente con Dios, solo queda que ésta sea una similitudo in ratione, es decir, una semejanza basada en las razones eternas, que no son más que Dios mismo, unas y mismas con su esencia suprema, pero que a nivel de las creaturas, fundan toda una diversa gradación de imitaciones, a las que Alejandro llama impresiones o vestigios del Creador ${ }^{100}$ y que se dan según "el más y el menos"101. En síntesis, en su calidad de vestigia, las creaturas atestiguan la potencia, sabiduría y bondad divina ${ }^{102}$, y en su calidad de imitaciones creadas o participaciones finitas del Ser en sí, ellas conducen a Aquel de quien son vestigios ${ }^{103}$.

Para el maestro franciscano -como también para San Agustín, en quien se inspira- hay una sola Semejanza en sí, que es el Verbo eterno, "expresa semejanza de Dios Padre"104, gracias al cual todas las cosas pueden imitar a Dios y convertirse en sus vestigios. O como lo expresa el Obispo de Hipona, solo al Verbo puede llamársele con propiedad Semejanza, no por participación de alguna otra semejanza, sino porque es la Primera Semejanza (prima similitudo), por cuya participación son semejantes todas las cosas que por ella creó Dios ${ }^{105}$. Y como Dios es Trinidad, habrá una triple impresión divina en cada creatura, en estricta concordancia con la causa omnipotente que la ha producido ${ }^{106}$. Como es manifiesto, nuestro autor defiende por doquier que la creación completa da testimonio de Dios como causa eficiente, ejemplar y final de todo lo

\footnotetext{
99 Alexandri de Hales, S.Th., II, Núm. 35, 1.

100 Alexandri de Hales, S.Th., II, Núm. 35, Respondendum.

101 AleXandri de Hales, S.Th., II, Núm. 37, Contra.

102 Alexandri de Hales, S.Th., II, Núm. 34, Solutio.

103 Alexandri de Hales, S.Th., II, Núm. 40, Solutio.

104 Alexandri de Hales, S.Th., I, Núm. 422, Respondeo.

105 SAn Agustín, De Genesi ad Litteram imperfectus Liber, XVI, 57: "Qua propter etiam similitudo Dei, per quam facta sunt omnia, proprie dicitur similitudo; quia non participatione alicuius similitudinis similis est, sed ipsa est prima similitudo, cuius participatione similia sunt, quaecumque per illam fecit Deus".

106 Alexandri de Hales, S.Th., I, Núm. 73, Respondeo.
} 
que es, e incluso más: el alma humana, más que vestigio trinitario es una imagen de la Trinidad "según la memoria, inteligencia y voluntad que hay en la mente (mens)"107, doctrina característica del naciente agustinismo franciscano medieval.

\section{LA COMPOSICIÓN EN LOS ENTES CREADOS}

Como hemos visto hasta aquí, Alejandro de Hales ha establecido una clara distinción entre Dios y las creaturas, destacando frecuentemente la absoluta simplicidad divina frente a la composición de los entes creados. Ya lo notamos, por ejemplo, con ocasión del tema de las Ideas divinas y el ejemplarismo. Así, en cuanto dependientes en el ser de su Creador, y por el hecho de haber sido sacadas de la nada, las creaturas no son su propio ser, sino que éste lo han recibido de Otro, que es su causa prime$\mathrm{ra}^{108}$. Desde esta perspectiva, el maestro franciscano distingue varios tipos de composición en los seres creados -unas secundum rationem, otras secundum rem-, doctrina que se aparta de la ontología de San Agustín, puesto que esta vez su fuente de inspiración es más bien aristotélica, árabe y judía que bíblica y agustiniana, pero que paradójicamente será reconocida como uno de los emblemas del llamado agustinismo medieval ${ }^{10}$.

La primera composición que afecta a los entes creados es la de quod est y quo est, que nuestro autor habría tomado de Boecio ${ }^{110}$, y que se encuentra en toda creatura. Para Alejandro, esta composición quod est-quo est es más común y naturalmente anterior que la composición de materia y forma ${ }^{111}$ debido a que se encuentra en las formas tomadas en sí mismas, donde no hay composición de materia y forma ${ }^{112}$. Incluso habría mayor unidad en el binomio quod est-quo est que en la composición de

107 Alexandri de Hales, S.Th., I, Núm. 417, Respondeo.

108 Alexandri de Hales, S.Th., II, Núm. 56, II, ad 1.

109 Tal como lo señala De Wulf, las teorías ajenas a San Agustín, pero que en la Edad Media gozan del status de agustinianas son todas las relativas a la materia y la forma. De allí surgirá el hilemorfismo universal y la doctrina de la pluralidad de formas sustanciales. M. De Wulf, Histoire de la..., 356.

110 Cfr. Ch. Cullen, "Alexander of Hales", en J. E. Gracia- T. B. Noone, A Companion to..., 107.

111 Alexandri de Hales, S.Th., II, Núm. 60, Solutio.

112 Alexandri de Hales, S.Th., II, Núm. 58, Solutio. 
materia y forma, puesto que en el primero un término se dice del otro, en cambio, entre materia y forma no se da esta convertibilidad ${ }^{113}$.

Sin embargo, Alejandro nunca da una definición categórica de cada término del binomio. No obstante, todo apunta a que el quod est dice relación con el ente concreto (un hombre) y el quo est con la esencia abstracta (la humanidad). En todo caso, esta es una distinción de razón (secundum rationem), de manera tal que entre el quod est y el quo est no hay distinción real ${ }^{114}$, como no la hay entre un hombre y su humanidad, aun cuando esta haya sido recibida de una Causa creadora. En cambio, al ser Dios absolutamente simple, hay en Él identidad total entre el quod est (Deus) y el quo est (Deitas) ${ }^{115}$, lo que indica que este binomio también se encuentra en la esencia divina, pero no bajo la razón de composición que se da en los entes creados, sino como incluido en su simplicidad, lo cual, de paso, hace que esta composición sea la más noble -dado su origen- que puede encontrarse en las creaturas ${ }^{116}$.

Por otra parte, según Alejandro de Hales, hay una segunda composición - esta vez de orden real o secundum rem- en todo lo creado, a saber, materia y forma. Esta composición, como lo destaca De Wulf, es llamada primus binarius materiae et formae ${ }^{117}$, se extiende a toda creatura, tanto corpórea como espiritual, y constituye el inicio de la doctrina del hilemorfismo universal que sostendrá toda la Escuela Franciscana, con la sola excepción de Juan de la Rochelle. Su origen se encuentra en Avicebrón, quien en su Fons Vitae (Mekor Hayyim) afirma que todas las sustancias del universo, incluidos los intelectos, las almas y los ángeles, están compuestos de materia y forma ${ }^{118}$. De un modo semejante, Alejandro asume este hilemorfismo universal al defender la composición de materia y forma en las sustancias espirituales ${ }^{119}$, es decir, en ángeles y almas humanas: "el alma no se dice simple, porque posee materia y forma espiritual" ${ }^{120}$. Esta doctrina, junto con el pluralismo de formas sustan-

113 Alexandri de Hales, S.Th., II, Núm. 60, ad 1-2.

114 Alexandri de Hales, S.Th., II, Núm. 58, ad 1.

115 Alexandri de Hales, S.Th., II, Núm. 59, Videtur, b.

116 Alexandri de Hales, S.Th., II, Núm. 61, Solutio.

117 Cfr. M. De Wulf, Histoire de la..., 107.

118 T. Rudavsky, "Avencebrol”, en J. E. Gracia- T. B. Noone, A Companion to Philosophy in the Middle Ages (Blackwell Publishing, Oxford, 2006) 176.

119 Alexandri de Hales, S.Th., II, Núm. 328, b.

120 Alexandri de Hales, S.Th., II, Núm. 56, Solutio, II, 2. 
ciales -también proveniente de Avicebrón- dará lugar al famosissimum binarium agustinianum, con el agravante que ninguna de estas teorías es de San Agustín, sino que provienen de elementos aristotélicos mezclados con influencias árabes y judías.

Ahora bien, más allá del eclecticismo presente en la doctrina hilemórfica halesiana, hay que recordar que el maestro franciscano, adhiriendo a San Agustín, sostiene que la creatura es un concreatum $^{121}$, donde tanto materia como forma han sido creadas por Dios ex nibilo y en la simultaneidad de su acto creador, es decir, no fue creada primero la materia y luego, tras un tiempo fueron creados los entes, sino que "al mismo tiempo pasaron del no-ser al ser los principios y lo que se hace a partir de ellos"122. Por lo tanto, al igual que San Agustín, Alejandro de Hales defiende la noción de creación como el radical paso del no-ser al ser de todo lo que la creatura es, en la simultaneidad del acto creador de Dios. No obstante, el fondo de la distinción halesiana entre materia y forma sigue siendo de raigambre aristotélica y judía (Avicebrón).

Dado este contexto, es preciso preguntarse ¿qué entiende exactamente nuestro filósofo por materia y forma? En primer lugar, ambos son los principios intrínsecos de que están compuestas todas las sustancias creadas $^{123}$, los cuales de suyo se ordenan el uno al otro mediante un apetito (appetitum) inserto en lo más íntimo de ellos, de modo que la materia apetece a la forma y la forma a la materia ${ }^{124}$. La forma, por su parte, es entendida aristotélicamente como "lo que da el ser a la materia y al mismo compuesto"125. En cuanto principio perfectivo interior, la forma ennoblece a la materia "por su [capacidad de] información y completitud" ${ }^{126}$, proporcionándole a la materia el acabamiento ontológico que por sí sola no puede tener. Finalmente, en el orden del conoci-

121 Alexandri de Hales, S.Th., II, Núm. 43, ad 1 a: "Consuevimus tamen creatum et concreatum sub uno generali nomine, scilicet creaturae, comprehendere, et sic creari est concreatum". Vid. también S.Th., II, Núm. 51, Solutio. Los textos paralelos en San Agustín pueden encontrarse en: De Genesi ad Litteram, I, 15, 29; Contra Adversarium Legis et Prophetarum, I, 12.

122 Alexandri de Hales, S.Th., II, Núm. 44, Respondendum. Sobre la reflexión halesiana en torno a la simultaneidad de la creación de materia y forma, vid. S.Th., II, Núm. 248, Solutio.

123 Alexandri de Hales, S.Th., I, Núm. 341, Solutio.

124 Alexandri de Hales, S.Th., II, Núm. 482, Respondeo.

125 Alexandri de Hales, S.Th., II, Núm. 51, Contra, 3.

126 AleXandri de Hales, S.Th., II, Núm. 453, ad 2. 
miento, la forma hace a la cosa cognoscible ${ }^{127}$ y apta para ser entendida en cuanto a su esencia propia.

La materia, en el pensamiento halesiano, es un principio determinable "porque carece de perfección"128, fórmula que sigue de cerca el concepto agustiniano de materia como informidad sin ninguna forma (Conf., XII, 3, 3) o informitas omnimoda (Conf., XII, 4, 4), sin embargo, ella es capax formarum ${ }^{129}$, dado su carácter eminentemente potencial y receptivo. Sorprende en este punto la fidelidad de Alejandro a Agustín: al declarar que la materia no es un puro no-ser, ya que posee la capacidad de recibir formas, lo que hace es corroborar la definición agustiniana de materia como capacitas formae $e^{130}$, en vistas de la constitución ontológica del ser creado.

En lo que respecta a su origen, Alejandro de Hales rechaza la eternidad de la materia y la posibilidad de que ella sea de la misma sustancia que el Creador, invocando la refutación agustiniana de De Civitate Dei, $\mathrm{X}, 31$ al argumento platónico del pie eternamente puesto en el polvo, e insistiendo en la prioridad tanto temporal como ontológica del Artífice sobre la materia y sobre todo lo creado ${ }^{131}$.

Luego, la materia es la primera cosa creada, es la terra invisibilis del relato genesíaco asimilada filosóficamente por el maestro franciscano -siguiendo a San Agustín- a la materia informe ${ }^{132}$. En ella distingue, además, la materia espiritualy la materia corporal: la primera no es sujeto del movimiento local ni del cambio sustancial, sino solo de la forma, siendo este el caso de los espíritus, llamados por ello, las creaturas más nobles de todas. Por el contrario, la materia corporal es materia subiecta motui et contrarietati, como en el caso de los elementos (materia corporal terrestre); en cambio, solo es sujeto del movimiento en el caso de los

127 Alexandri de Hales, S.Th., II, Núm. 453, Solutio.

128 Alexandri de Hales, S.Th., I, Núm. 34, ad 1.

129 AleXandri de Hales, S.Th., II, Núm. 248, Ad obiecta, b.

130 Cfr. San Agustín, De Natura Boni, XVIII.

131 Alexandri de Hales, S.Th., II, Núm. 5, Quod sic, 2. La conclusión del argumento halesiano no puede ser más enfática: "sed sicut aeternitas praecedit 'nunc' temporis, ita essentia opificis praecedet materiam; non ergo erit materia ab opifice et aeternaliter ens".

132 Alexandri de Hales, S.Th., II, Núm. 254, Solutio: "Vel per terram et aquam, sicut dicit Augustinus Contra Manichaeos, intelligitur materia informis, quae se habet ad omnia”. Cfr. San Agustín, De Genesi contra Manichaeos, I, 7, 12 y Conf. XII, 4, 4. 
cuerpos celestes incorruptibles (materia corporal celeste) ${ }^{133}$. En buenas cuentas, Alejandro replica acá la distinción aristotélica -mediatizada por el hilemorfismo de Avicebrón- que establece diferentes tipos de materia dependiendo del compuesto que forman, a saber, entes espirituales, entes corporales terrestres o supracelestes ${ }^{134}$, pero en el contexto mayor de la exégesis bíblica de los conceptos de caelum et terra que ha heredado de los Padres de la Iglesia.

En síntesis, el Doctor de Hales sostiene categóricamente el hilemorfismo universal, al cual asocia una incipiente y aún no desarrollada doctrina de la pluralidad de formas sustanciales, la que será explicitada más tarde por su discípulo, San Buenaventura. En el caso del hombre, es claro que, para Alejandro, hay pluralidad de formas sustanciales: "el alma tiene su propia materia espiritual y se une al cuerpo, que tiene, a su vez, su forma de corporeidad" 135 . Pero, pareciera ser que antes del advenimiento de cualquier determinación entitativa habría en toda creatura una primera disposición que identifica con la luz (lux). En efecto, remontándose a una larga tradición patrística e incluso neoplatónica, y bajo la indudable influencia de San Agustín y del tratado De luce de Roberto Grossetes$\mathrm{te}^{136}$, nuestro autor concibe a Dios como la Luz suprema, como aquel sol spiritualis que ilumina a todo lo que ha sido hecho por É ${ }^{137}$. Por lo

133 Alexandri de Hales, S.Th., II, Núm. 249, Solutio, ad 1.

134 Alexandri de Hales, S.Th., Núm. 249, Solutio, ad 1: "Non ergo est communis materia spirituum et corporum nec corporum supercaelestium et inferiorum secundum Philosophum”. La influencia de la noción de materia de Avicebrón es clarísima. Como comenta Rudavsky, "types of matter are ordered in a hierarchy that corresponds to a criterion of simplicity: general spiritual matter; general corporeal matter; general celestial matter; general natural matter; and particular natural matter. Individual matter is associated with prime matter, which lies at the periphery of the hierarchy, thus epitomizing the very limits of being. Each level of matter is coarser ontologically than its predecessor". T. RUDAVSKY, "Avencebrol", en J. E. Gracia- T. B. Noone, A Companion to Philosophy..., 176-177.

135 F. Canals Vidal, Historia de la Filosofia Medieval (Herder, Barcelona, 1976) 194.

$136 \mathrm{Al}$ respecto, vid. J. Mc Evor, "The Metaphysics of light in the Middle Ages", en Philosophical Studies Dublin 26 (1979) 126-145. Ciertamente, "the main point of Grosseteste's doctrine is that light is the prime bodily form. At the beginning of time, God has created a point of light as the first form of the prime matter". L. Miccoli, "Two thirteenth-century theories of light: Robert Grosseteste and St. Bonaventure", en Semiotica 136 1/4 (2001) 74.

137 Alexandri de Hales, S. Th., I, Núm. 282, ad 1. En S.Th., I, Núm. 89, ad 6, llama a Dios fons lucis spiritualis y lux ipsa intelligibilis, en un lenguaje deudor de la noción 
tanto, la luz es una disposición común (communis dispositio) a los seres corporales y espirituales ${ }^{138}$, la que hace relucir a cada ente según su grado de participación de la Luz eterna ${ }^{139}$. No obstante, el maestro halense no precisa si esta dispositio es o no la primera forma de las creaturas; lo que sí es claro es que, después de él, la Escuela Franciscana afirmará con fuerza que "la corporeidad que da la primera forma de la luz es el primer acto de la materia prima, y permanece unida a ella inseparablemente a través de todas las mutaciones sustanciales o accidentales" ${ }^{\prime 140}$.

\section{LA SIMULTANEIDAD DE LA CREACIÓN Y SU DESPLIEGUE TEMPORAL}

Como ya hemos visto, para Alejandro de Hales Dios ha creado el mundo simul, en un solo acto de su omnipotencia, de manera tal que la creación de géneros y especies quedó instaurada en la obra de los seis días $^{141}$, como lo sostiene el mismo Agustín (De Gen. ad Litt., IV, 33, 52) y una larga tradición patrística. Sin embargo, y pese a que en un sentido la creación está ya acabada, Dios continúa obrando hasta el presente, multiplicando los seres, gobernando la creación y haciendo milagros ${ }^{142}$. De esta manera, el maestro de Hales adhiere también a la idea de que Dios gobierna el desarrollo de los géneros creados en los seis días del Génesis, tal como lo sostuvo la interpretación de Io., V, 17 del Obispo de Hipona ${ }^{143}$. Así, para compatibilizar la creación simultánea con la continua cooperación divina en el desarrollo de la naturaleza, el Doctor Irrefragabilis recoge la doctrina agustiniana de las razones seminales y la inserta en su particular concepción de materia y forma.

En primer lugar, según el pensamiento halesiano, las razones seminales son "ciertas formas inducidas por el Creador" ${ }^{144}$, entendidas como causas originales o primordiales creadas por Dios según las cuales -des-

agustiniana de Dios como lux vera. Vid. F.-J. Thonnard, "La notion de Lumière en philosophie augustinienne", Recherches Augustiniennes, Hommage au R.P. Fulbert Cayré (Vol. II; Études Augustiniennes, Paris, 1962) 125-175.

138 Alexandri de Hales, S.Th., I, Núm. 175, ad 1.

139 Alexandri de Hales, S.Th., I, Núm. 46, ad 2.

140 G. Fraile, Historia de la Filosofía (Tomo II-2; B.A.C, Madrid, 1983) 141.

141 Alexandri de Hales, S.Th., II, Núm. 45, Solutio, ad 3.

142 Alexandri de Hales, S.Th., II, Núm. 45, Solutio, ad 3.

143 Cfr. San Agustín, De Genesi ad Litteram, V, 20, 40: "[...] usque nunc operari Deum, ut, si conditis ab eo rebus operatio eius subtrahatur, intercidant".

144 Alexandri de Hales, S.Th., II, Núm. 45, Solutio, ad 1. 
pués de un tiempo oportuno- llegan al ser los entes naturales, de acuerdo a la gradación ontológica marcada por lo superior y lo inferior ${ }^{145}$. Al igual que San Agustín, Alejandro les atribuye una naturaleza simple e incorpórea, opuesta a la naturaleza material de los elementos, con capacidad para hacer surgir, desde la virtus operativa de plantas y animales, y con la concurrencia de la influencia de los astros, nuevos entes de la misma especie ${ }^{146}$, supuesto, como ya se dijo, el tiempo oportuno de su eclosión ${ }^{147}$.

Estas razones seminales se encuentran en lo más recóndito de la materia, en estado virtual o latente; de hecho, ellas disponen la causa material para el cambio, puesto que son formas en estado germinal ${ }^{148}$. Luego, no es que Dios intervenga en la producción de cada nueva forma y del consiguiente compuesto que llega al ser, es decir, no es necesario que cada nueva forma sea creada ex nibilo en cada caso, sino que, mediante esta naturaleza impregnada de formas incoadas en el seno de la materia, Dios induce la forma por generación, tal como -en la analogía propuesta por Alejandro de Hales- el fuego produce fuego y la luz produce luz (ignis ex igne, lumen ex luce $)^{149}$. Así, enfrentado a la misma dificultad que el Santo de Hipona, Alejandro resuelve del mismo modo el caso de los sucesos extraordinarios: en el caso del milagro o de los hechos prodigiosos que se encuentran fuera del decurso usual de la naturaleza, esto es, fuera del normal desenvolvimiento de los seres a partir de su correspondiente razón seminal, es Dios quien se reserva la producción de la forma, aun cuando para ello se valga del concurso de ángeles o humanos ${ }^{150}$.

145 Alexandri de Hales, S.Th., II, Núm. 45, Solutio, ad 2. La filiación agustiniana de esta doctrina no puede ser más evidente: el mismo Alejandro cita dos veces $D e$ Trinitate, III, 9, 16, a fin de respaldar su propia concepción de las razones seminales. Sobre el conjunto de lo sostenido por el Maestro de Hales acerca de este tema, los Padres Editores de Quaracchi comentan: "his dictis patet quod sententiam S. Augustini clare proponat Alexander”. Alexandri de Hales, S. Th., II, Prolegomena, XXXVII.

146 Alexandri de Hales, S.Th., II, Núm. 481, ad 5. Cfr. San Agustín, De Genesi ad Litteram, V, 23, 44.

147 Alexandri de Hales, S.Th., I, Núm. 154, Solutio. Cfr. San Agustín, De Trinitate, III, 9, 16.

148 Cfr. Ch. Cullen, "Alexander of Hales", en J. E. Gracia- T. B. Noone, A Companion to..., 107. Cfr. San Agustín, De Genesi ad Litteram, VII, 22, 32.

149 Alexandri de Hales, S.Th., II, Núm. 45, Solutio, ad 1.

150 Alexandri de Hales, S.Th., II, Núm. 45, Solutio, ad 1: "In iis quae fiunt mirabiliter, dispositio fit per angelos vel per homines, ipsa vero forma fit a Deo". Para 
En síntesis, si bien nuestro autor no desarrolla de manera acabada la doctrina de las razones seminales -como lo hace San Agustín-, sí la utiliza profusamente para dar razón de la contingencia y el cambio en el mundo, dejando clara la compatibilidad entre la creación simul de todo lo que es y el despliegue temporal de los seres creados desde el principio solo en su razón causal. Posteriormente, San Buenaventura y el resto de la Escuela Franciscana medieval entenderán las nociones de materia y razones seminales como inchoatio formae, alejándose cada vez más de su original sentido agustiniano y dando paso, además, a las más intensas controversias metafísicas entre franciscanos y dominicos del siglo XIII.

\section{CONCLUSIONES}

Como hemos visto, Alejandro de Hales no solamente ha sido el primer maestro franciscano en las cátedras de París y el fundador de la Escuela de la orden, sino que también, con toda justicia, podría considerársele como uno de los más notables agustinistas del siglo XIII respecto del tema de la creación del mundo. De hecho, en las páginas precedentes hemos podido constatar que Alejandro defiende un gran número de nociones agustinianas asociadas a la creación, tales como el sentido de la fórmula creatio ex nibilo, la creación temporal, las Ideas divinas y el ejemplarismo, las razones seminales y la simultaneidad del acto creador de Dios en perfecta armonía con el despliegue temporal de la creación. En todos estos casos, al desarrollar sus propios argumentos, no vacila en citar como autoridad a San Agustín e incluso adjuntar copiosos textos tomados de las principales obras en que el Obispo de Hipona trata la creación.

Además, cabe señalar que la elaboración intelectual halesiana sobre la creación no se limitó simplemente a recoger los elementos doctrinales que la máxima auctoritas de la época en filosofía y teología podía proporcionar, sino que buscó integrar, mediante un notable esfuerzo intelectual, múltiples nociones provenientes de otras tradiciones, incluso paganas o infieles. Nada más característico de lo anterior que el modo como Alejandro acoge la terminología metafísica aristotélica, pero mediatizada por la interpretación que Avicebrón le impone, por ejemplo,

respaldar esta afirmación cita el conocido texto de San Agustín, De Trinitate, III, 9, 17: "Qualibuscumque angelis vicinas causas ex elementis contrahere quanto facilius est, tanto mirabiliores in huiusmodi operibus existent eorum celeritates". 
al hilemorfismo del Estagirita. En consecuencia, el maestro de Hales acaba por asumir estas nuevas ideas sobre el hilemorfismo universal y el pluralismo de formas sustanciales en concordancia con el agustinismo que profesa, y, lo más importante, lo hace con la convicción de estar interpretando razonadamente las Sagradas Escrituras, esto es, siguiendo el lema del Santo Doctor acerca de la intelección de la fe.

Con todo, la influencia de la doctrina de la creación forjada por la mente agustiniana es patente en los argumentos y las afirmaciones que Alejandro realiza en torno al tema del acto creador divino. El grueso de su elaboración intelectual está apoyada por los textos clásicos de Confesiones, De Trinitate, De Civitate Dei, De Natura Boni, entre otros, y obviamente los tres comentarios al Génesis de San Agustín. No obstante, el maestro halense no se limita a citar y parafrasear a su inspirador, sino que reinterpreta conceptos agustinianos claves como creatio ex nibilo, Dios como causa ejemplar, la participación de las ideas divinas, la semejanza en sí, la creatura como concreatum, la materia como depositaria de las razones seminales y los dos sentidos de la creación (simultánea y desplegada en el tiempo), dándoles una significación más amplia e inclusiva -respecto de las influencias filosóficas de su propia época- que lo hacen el autor de una renovada síntesis metafísica frente al tema que nos ocupa. Finalmente, en cuanto a la noción de creación, podemos afirmar que Alejandro de Hales inaugura una nueva tradición interpretativa de la metafísica agustiniana -la cual será asociada rápidamente a la naciente Escuela Franciscana-, y que madurará y dará frutos en su discípulo más notable, San Buenaventura. 